\title{
INVESTIGATION OF SEEPAGE EFFECT ON RIVER DIKE'S STABILITY UNDER STEADY STATE AND TRANSIENT CONDITIONS
}

\author{
${ }^{1}$ Alban KURIQI, ${ }^{2}$ Mehmet ARDIÇLIOGLU, ${ }^{3}$ Ylber MUCEKU \\ ${ }^{1}$ Illyrian Consulting Engineers sh.p.k, Rr. Andon Zako Cajupi, Nd. 14, H. 14, Ap. 2, \\ 1019, Tirana, Albania, e-mail: albankuriqi@ gmail.com \\ ${ }^{2}$ Civil Engineering Department, Engineering Faculty, Erciyes University, 38039, Kayseri, \\ Turkey, e-mail: mardic@erciyes.edu.tr \\ ${ }^{3}$ Institute of Geosciences, Energy, Water and Environment, Polytechnic University of Tirana, \\ Don Bosko nr.60, 1024, Tirana, Albania, e-mail: mucekuy@yahoo.com
}

Received 14 November 2015; accepted 22 March 2016

\begin{abstract}
World experiences reveal that catastrophic floods are posing a serious threat that comes not only from them as extreme events but also as the result of adaptation measures uncertainty, (i.e. dikes). In particularly old dikes constructed earliest at the north part of Albania, during the last floods demonstrated the high uncertainty and weak spots. In this paper, the significance of the seepage investigation and stability analysis are discussed. As a case study, parts of new dikes constructed last years along the Buna River located in north part of Albania are investigated. Filling materials for these dikes are represented mostly from silt and clay. Finite element method is used to perform seepage analysis while general limit equilibrium method is used to perform slope stability analysis. Both, seepage and slope stability analyses are done for three different scenarios: steady state, rapid filling, and rapid drawdown. Finally, it is concluded that silt-clay material used in these dike structure is posing serious uncertainty during seepage phenomenon by threatening the stability of entire dike structure especially during the transient condition (rapid filling and drawdown).
\end{abstract}

Keywords: Dike, Seepage, Slope Stability, Rapid Filling, Rapid Drawdown

\section{Introduction}

It is evident that considerable numbers of inhabitants are located closer to lakes, shoreline, and rivers valley. In one point of view, establishment of high percentage of inhabitants to the aforementioned locations has many opportunities but on the other hand, these locations are vulnerable from different kinds of threat posed from extreme events as increase of sea level, high magnitude of wave and flooding events. Periodically floods pose a serious threat to human life, valuable property and city 
infrastructure, [1], [2]. Construction of the adaptation and defenses systems is dating very earlier in human being history. Adaptation systems are represented by structures as dikes or embankment, which has two main purposes; to retain and diverting certain amount of water that comes especially during flood events, [3], [4]. The first measures to be adopted against these extreme events and to avoid drastic damages is related to better conception of adaptation structures by considering different records from flood events, [5]. In the past, construction of these kinds of structures generally has been carried out by using simple procedures and equipment. In this context the older dikes or embankment structures in generally, are presenting high index of risk related to failure, especially during flood events, [6], [7]. The main factors that influence a dike failure depends mostly from: type of materials (heterogeneity), used as filling material, not sufficient compaction during the construction phase, which leads to the softening and loosening of filling materials.

Adaptation measures against natural hazards [8] or those initiated by man-made are one of the main challenges, going to the past it is obvious that a serious effort is taken from people after they are affected especially from flood disasters. During the last decades, floods probability of occurrence has increased in terms of the return period (i.e. probability exceedance). So having sufficient information on earth structures and specifically on dike performance is very important in order to have clear picture about dike stability against different factor that cause failure of structure itself, [9], [10]. In this paper, seepage effects on dike structures stability during steady state and transient conditions are discussed. Additional factors that cause instability or in worse case total failure of earthen dike structure in generally are: surface erosion, piping and seepage. From these three factors, erosion can be consider as less threat factor that may cause failure of dikes since it occurred at the outer part of the structure, so it can be controlled. On the other hand, piping, which is considered as one of the main factors that cause failure of earth structures all over the world, occurs due to the migration of small soil particles into the coarse materials. This phenomenon takes place through the dam or dike body, or under the structure foundation, [11], [12].

While the phenomenon of seepage that is discussed mostly in this paper represent the uncontrolled saturation of filling materials inside the dike or earth structures in generally. In this context, the stability of dikes is assessed for steady state and transient condition. Steady state condition consists into the investigation of seepage effect on dike stability when water level does not change. While transient condition is regarding with phenomena known as rapid filling or rapid drawdown, which occurs during the sudden change of water level (increments and decrements), which modifies flow condition and effect directly soil properties inside the dike structure. Numerical modeling based on finite element method is used to analyze the seepage for respective conditions (i.e. steady state and transient). Finally, achieved results are compared for both conditions and some main conclusion and recommendations are addressed to the protection of dikes or embankment structures. 


\section{Structural failures}

\subsection{Dike breaching mechanisms}

Failures of an earth structure involve the separation (rupture) of the embankment material or its foundation depending on geotechnical conditions of the basement. This type of failure is more prominent in large dams or embankment structures. However, it is not exclusive to only large dams; similar occurrences happen on small earthen embankments or dikes, [13], [14]. It is noticed that the failure of earth structures may be caused due to different factor as construction activities, rainfall infiltration, also many failures occur in natural soil slopes and excavated slopes. In many cases, stability problems of embankments structures and dikes occur during the rapid filling of reservoir or waterways and rapid drawdown, [15].

According to 'Voorschrift Toetsen op Veiligheid'; National Protocol for Safety Assessment of dikes in Netherlands [16], safety assessment of dikes should be done by considering one of the 9 potential failure mechanisms: slide circle inside slope, settlement, slide circle outside slope, piping, wave overtopping, erosion outside slope, micro instability, softening and erosion foreland. Generally, natural soils are characterized from high variability and heterogeneity, these characteristics as mentioned above has a significant indication on physical-mechanical properties of the soil. One of the main sources of heterogeneity is inherent spatial soil variability due to the different depositional conditions and different loading histories, [17], [18], [19].

Breach mechanism is classified as following: hydraulic failure, geo-hydraulic failure and global static failure, [20]. Hydraulic failure generally consists on overtopping [21] and wave scour on the dike structure, while geo-hydraulic failure is due to the seepage process through the dike core or foundation, which leads into the erosion process associated with transportation of significant materials amount. Whereas concerning to the type of breach mechanisms, if two aforementioned types are induced mainly from pressure forces as ice, water, and wind waves, while the third type of breach mechanisms (i.e. global static failure) is due to gravity and pressure forces occurring as local or total failure of the dike structure.

\subsection{Seepage phenomenon}

Analyzing seepage phenomenon occurred in: earth irrigation system, storages, ponds and other earth structure as dikes or earth dams is very important task to be carry out in order to avoid any threat that may come as result of any possible failure, [22]. Earliest, attention has been given generally on estimation of seepage loose regarding especially to channel system and storage dam, while nowadays is given attention both amount of water loose and impact on environmental degradation, [23]. Identification and estimation of seepage phenomenon are very important issue for design and construction in particularly for the earth dams and dike structures, [24]. In order to decrease the path of flow line, which represents the seepage phenomenon through the earth structure, designers proposing to use one of the following measures: impervious core, upstream clays and blanket or cut-off trench. Still, even significant advancement achieved in the field of geotechnical engineering, excessive seepage under or through the structure, 
threatens seriously the integrity of the structure, [25], [26]. In unconfined zone regarding the earth structures, seepage origin is linked also with the free surface of the structure. Free surface at the mean time play two different roles: it behaves as path of streamline and as boundary condition within the seepage network by hindering the procedure of calculation, [27], [28]. As mentioned above during flood events, seepage phenomena are one of the main factors that induce failure of dike structures. The instantaneous increase and decrease of water level at the river dike during the floods, induce a typical unstable seepage process, moreover in these conditions a significant deformation of structure can occur, [29].

\section{Problem statement}

Floods are natural phenomena, which happening very often especially in the northwest part of Albania [30], (Fig. 1). During floods, water occupy for hours in case of flash floods, or days in case of long-term floods that occurs generally during the winter; when rainfall period is longer or spring as result of snowmelt, [31].

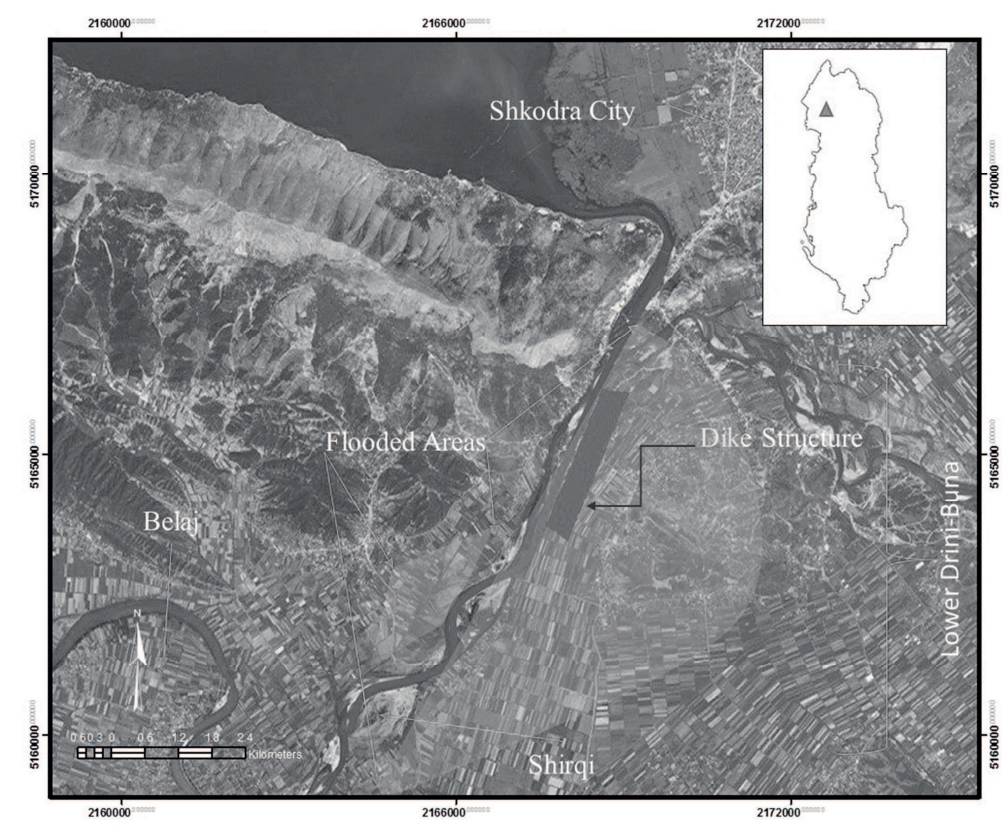

Fig. 1. Flood plan map of Buna River in Shkodra city and surrounding areas, located at north-west of Albania

An unacceptable high risk of flood characterized the land of the Lower Drini-Buna River basin, this is due to significant geological changes that happen last 150 years ago. Along the Buna River flow, adaptation measures are constructing continuously, especially after floods of winter 2010. Despite new protection structures constructed 
after winter 2010, in addition, there is done reinforcement of the existing dikes. The elevation of the existing dikes on the left bank of the Buna is placed in accordance with an international agreement between Albania and Montenegro. This level provides protection against the calculated flow discharge $2 \%$ exceedance probability (i.e. 1-50-years), [32]. Even if flow substantially in excess of the 100-year design flood arrives at Shirqi, a weir is designed such that the excess flow, above the 50-year discharge, is diverted out of the river and across Trushi Field towards Murtemza. The Shirqi to Belajdikes and the Pentari to Pulaj dikes, when rehabilitated to internationally agree levels, are protecting the south-west of the study area, including the town of Velipoja for excess flow, 1 to 50-year exceedance probability. Since in the Buna River, continuously is occurring rapid filling and drawdown, this process leads to seepage phenomenon even during the construction phase. In addition, this may affect the stability of protection structures, especially earth structures (i.e. dikes). In this case as mentioned above, seepage and stability of dike analysis is conducted by considering different scenarios: steady state, rapid filling, and rapid drawdown.

\section{Materials and methods}

\subsection{Materials}

During the construction phase of dikes placed along the Buna River, raw materials used for construction the dikes structures are represented mostly from silt-clay. Detailed data information about materials shown below (Table I) are obtained after in situ testing.

\section{Table I}

Materials properties used for dike construction

\begin{tabular}{|c|c|c|c|}
\hline \multirow{2}{*}{$\begin{array}{c}\text { Type of } \\
\text { Construction } \\
\text { Materials }\end{array}$} & \multicolumn{2}{|l|}{ Parameters } & \multirow[t]{2}{*}{ Quantity } \\
\hline & Notations & Symbols & \\
\hline Silt-Clay & $\begin{array}{l}\begin{array}{l}\text { Hydraulic Conductivity }(\mathrm{m} / \mathrm{h}) \\
\text { Volumetric Water Content }\end{array} \\
\left(\mathrm{m}^{3} / \mathrm{m}^{3}\right) \\
\text { Saturated Volumetric Water } \\
\text { Content }\left(\mathrm{m}^{3} / \mathrm{m}^{3}\right) \\
\text { Residual Water Content } \\
\left(\mathrm{m}^{3} / \mathrm{m}^{3}\right) \\
\text { Minimum Suction }(\mathrm{kPa} \\
\text { Maximum Suction }(\mathrm{kPa}) \\
\text { Unit Weight }\left(\mathrm{kN} / \mathrm{m}^{3}\right) \\
\text { Cohesion }(\mathrm{kPa}) \\
\text { Friction Angel (degree) } \\
\text { Curve Fitting Parameter } \\
\text { Curve Fitting Parameter }\left(\mathrm{cm}^{-1}\right)\end{array}$ & $\begin{array}{c}K_{\text {saturation }} \\
\theta_{w} \\
\Theta_{s} \\
\Theta_{r} \\
S_{\min } \\
S_{\max } \\
\gamma \\
C \\
\phi^{\prime} \\
n \\
\alpha\end{array}$ & $\begin{array}{c}0.0036 \\
0.08 \\
0.55 \\
\\
0.18 \\
\\
0.01 \\
1000 \\
17 \\
15 \\
20 \\
1.3 \\
0.78\end{array}$ \\
\hline
\end{tabular}


Volumetric water content is predicted by using Van Genuchten method as given in Eq. (1):

$$
\Theta_{w}=\Theta_{r}+\frac{\Theta_{S}+\Theta_{r}}{\left[1+\left(\frac{\Psi}{a}\right)^{n}\right]^{m}},
$$

where, $\Theta_{w}$ is the volumetric water content; $\Theta_{S}$ is the saturated volumetric water content; $\Theta_{r}$ is the residual water content; $\Psi$ is the negative pore-water pressure; and $a, n, m$ are curve fitting parameters. According to Van Genuchten method, curve-fitting parameters are estimated based on volumetric water content of soil. Therefore, the best point to estimate and evaluate the curve fitting parameters is the middle point between residuals and saturated water content, [33], [34].

The slope of curve can be estimated by using Eq. (2) as following:

$$
S_{p}=\frac{1}{\Theta_{S}-\Theta_{r}}+\frac{d \Theta_{p}}{d\left(\log \Psi_{p}\right)},
$$

where, $\Theta_{p}$ is the volumetric water content at middle point; $\Psi_{p}$ is the matric suction at middle point. While parameters $a$ and $m$ are estimated as following by Eq. (3) and Eq. (4):

$$
\begin{aligned}
& m=1-\exp \left(-0.8 S_{p}\right), \\
& a=\frac{1}{\Psi}\left(2^{1 / 2}-1\right)^{1-m} .
\end{aligned}
$$

Based on Van Genuchten method, hydraulic conductivity of soil can be estimated by Eq. (5);

$$
k_{w}=k_{S} \frac{\left[1-\left(a \Psi^{n-1}\left(1+a \Psi^{n}\right)^{-m}\right)\right]}{\left(1+a \Psi^{n}\right)^{m / 2}},
$$

where, $k_{w}$ is the hydraulic conductivity; and $k_{S}$ is the saturated hydraulic conductivity. Relation between matric suction, volumetric water content and conductivity are presented below, (Fig. 2). Within the increase of matric suction, volume water content 
and conductivity are decreasing because of compaction and consolidation process, which leads to increase of soil density, [35].

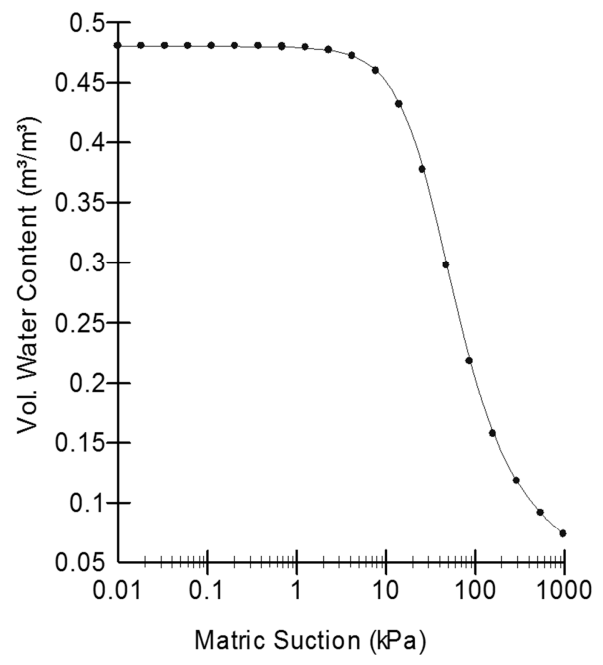

a)

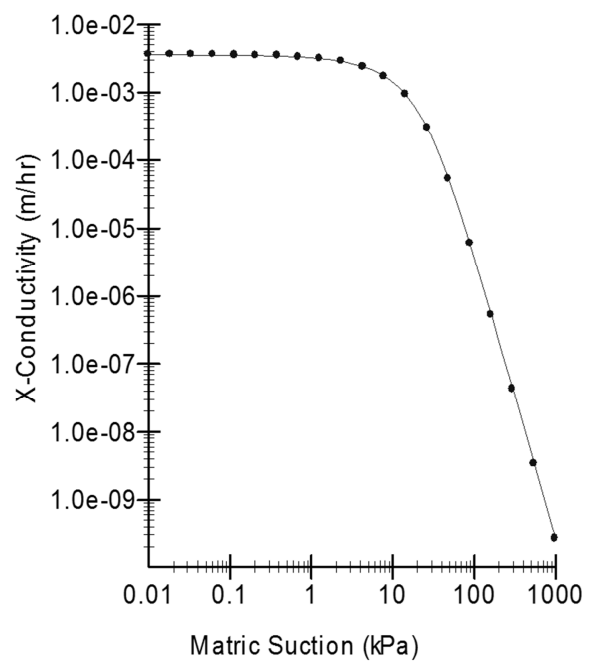

b)

Fig. 2. Graphical representation of a) volumetric water content vs. matric suction; b) conductivity vs. matric suction

\subsection{Methodology}

There are many numerical methods and models used to investigate seepage behavior. These common methods are represented by finite difference, boundary elements, finite volume and finite element methods. From all of these methods, finite elements methods are the most powerful and wide range of use relating to different engineering problems, [36]. In this study, seepage and slope stability problems are investigated for two different stages, respectively: steady state and transient condition. For this purposes 'Seep/W' package program that is developed by Geo-Slope International Ltd, which is based on Finite Element Methods (FEM) is used. Concerning to the transient conditions, it consists in two different scenarios, rapid filling, and rapid drawdown. Time of rapid filling is consider 12 hours, while a time of rapid drawdown is consider 156 hours (i.e. 6.5 days). Concerning to the geometrical configuration of dike, (Fig. 3) high of dike is $9 \mathrm{~m}$ including foundation, top of dike $5 \mathrm{~m}$, cross-section (width of the dike) is about $45 \mathrm{~m}$ and both slopes are 1:2.5. In addition in Fig. 3 the Minimum Water Level (Min.W.L), the Normal Water Level (N.W.L) and the Maximal Water Level (Max.W.L) are shown, respectively. The dike is discretized in triangle mesh with dimension $0.3 \mathrm{~m}$ each of them. 


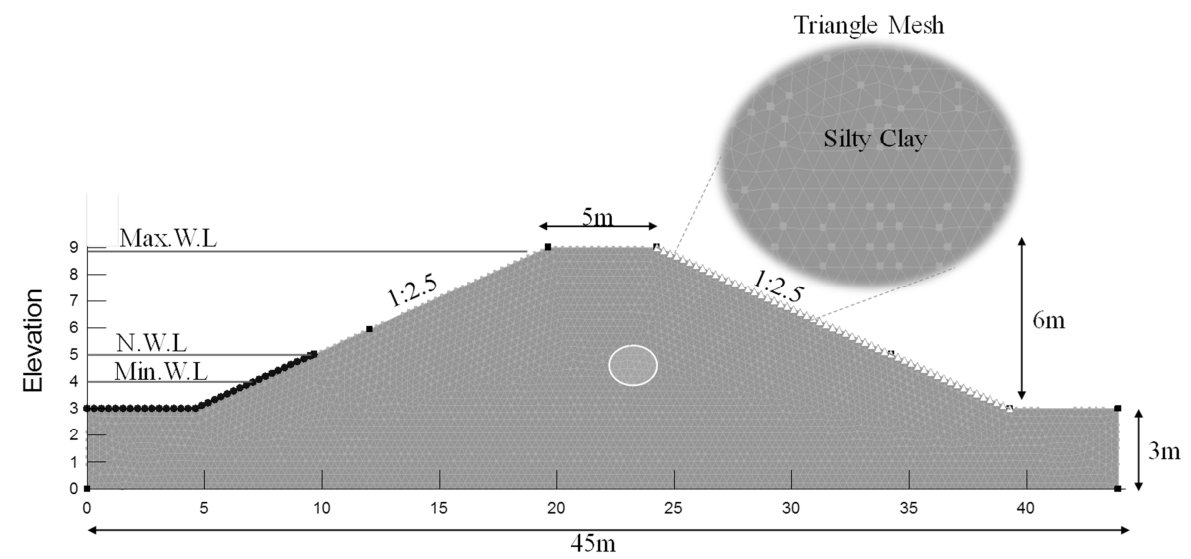

Fig. 3. Geometrical configuration of dike and discretization with triangle mesh elements

\subsection{Governing equations}

\section{Seepage}

Water flowing through the dike in both conditions (saturated/unsaturated), follows the Darcy law Eq. (6).

$$
q=k i
$$

where; $q$ is the specific discharge; $k$ is the hydraulic conductivity and $i$ is the hydraulic gradient. While two dimensional seepage flows through the soil for steady state is derived by using Eq. (7) as following:

$$
\frac{\partial}{\partial x}\left(k_{x} \frac{\partial H}{\partial x}\right)+\frac{\partial}{\partial y}\left(k_{y} \frac{\partial H}{\partial y}\right)+Q=\frac{\partial \theta}{\partial t}
$$

where, $H$ is the total head; $k_{x}$ is the hydraulic conductivity in the $x$-direction; $k_{y}$ is the hydraulic conductivity in the $y$-direction; $Q$ is the flux; $t$ is the time; and $\theta$ is the volumetric water content. From this equation state is noticed that, amount of the rate of flows changes in both directions $(x$, and $y$ ) by taking in account external applied flux is equal with rate of change of the volumetric water content for certain time, [35]. For steady state conditions, amount of water flux entering in certain volume of soil is equal with the escaping water flux, whereas Eq. (7) reduced as below Eq. (8):

$$
\frac{\partial}{\partial x}\left(k_{x} \frac{\partial H}{\partial x}\right)+\frac{\partial}{\partial y}\left(k_{y} \frac{\partial H}{\partial y}\right)+Q=0
$$


Concerning to the transient condition, two-dimensional flow through the soil is described as following Eq. (9):

$$
\frac{\partial}{\partial x}\left(k_{x} \frac{\partial H}{\partial x}\right)+\frac{\partial}{\partial y}\left(k_{y} \frac{\partial H}{\partial y}\right)+Q=m_{w} \gamma_{w} \frac{\partial H}{\partial t},
$$

where, $m_{w}$ is the slope of water content; $\gamma_{w}$ is the water content unit weight; $k_{x}$ is the hydraulic conductivity according to $x$-direction; $k_{y}$ is the hydraulic conductivity according to $y$-direction; $Q$ applied boundary flux; $m_{v}$ is slope of storage curve; $H$ is the total head and $y$-direction according $y$-axis.

According to Galerkin method of residual weighed to the governing differential equation, the finite element equation for two-dimensional seepage can expressed by (10) as following:

$$
\tau \int \mathbf{B}^{T} \mathbf{C B} d A \mathbf{H}+\tau \int_{A} \lambda \mathbf{N}^{T} \mathbf{N} d A \mathbf{H}, t=q \tau \int_{L} \mathbf{N}^{T} d L,
$$

where, $\mathbf{B}$ is the gradient matrix; $\mathbf{C}$ is the hydraulic conductivity matrix; $\mathbf{H}$ is the nodal vector; $\mathbf{N}$ is the vector of interpolation function; $q$ is the unit flux; $\tau$ is the thickens of the mesh element; $t$ is the time; $\lambda$ is the storage parameter, for case of transient seepage $\lambda=m_{w} \gamma_{w} ; A$ is the designation for summation over the area of given element; and $L$ is the designation for summation over the edge of an element [37]. Since Seep/W package of Geo-Slope International Ltd software, uses the backward differences method so Eq. (10) can be written in simplified form as given Eq. (11):

$$
(\Delta t \mathbf{K}+\mathbf{M}) \mathbf{H}_{1}=\Delta t \mathbf{Q}_{1}+\mathbf{M} \mathbf{H}_{0},
$$

where $\mathbf{K}$ is the hydraulic conductivity matrix; $\mathbf{M}$ is the water storage matrix; $\mathbf{Q}_{1}$ is the nodal flux vector at end of time increment; $\mathbf{H}_{1}$ is the head at the end of time increment; $\mathbf{H}_{0}$ is the head at the start of time increment and $\Delta t$ is the time increment.

\subsection{Slope stability}

As it is mentioned above for both scenarios (i.e. steady state and transient condition), slope stability of dikes is evaluated. Slope/W package based on general limit equilibrium method that include key elements of other methods like Ordinary, Bishop, Janbu and Spencer. In this study, Spencer method is used, which based on two factors of safety equations. These factors of safety can be estimated in two different ways: with respect to moment equilibrium Eq. (12) and horizontal force equilibrium Eq. (13), governing equations are as following: 


$$
\begin{aligned}
& F_{m}=\frac{\sum\left[c^{\prime} \beta R+(N-\mu \beta) R \tan \phi^{\prime}\right]}{\sum W x-\sum N f \pm D d}, \\
& F_{f}=\frac{\sum\left[c^{\prime} \beta \cos \alpha+(N-\mu \beta) \tan \phi^{\prime} \cos \varepsilon\right]}{\sum W \sin \alpha-D \cos \omega},
\end{aligned}
$$

while normal force is estimated as following Eq. (14 ):

$$
N=\frac{W+\left(X_{R}-X_{L}\right)-\frac{c^{\prime} \beta \sin \alpha+\mu \beta \sin \alpha \tan \phi^{\prime}}{F}}{\cos \alpha+\frac{\sin \alpha \tan \phi^{\prime}}{F}},
$$

where, $N$ is the normal force at slice base; $X_{R}$ is the inter-slice shear force; $X_{L}$ is the inter-slice shear force on either side of slice; $F_{m}$ is the factor of safety; $W$ is the slice weight; $\beta$ is the inclination angel; $c^{\prime}$ is the soil cohesion; $\phi^{\prime}$ is the internal friction angel; $\alpha$ is the inclination of the slice base; $D$ is the concentrated point load and $R$ is the geometric parameter. Dike is analyzed in saturated and unsaturated condition [38], described respectively by Eq. (15) and Eq. (16) as following:

$$
\begin{aligned}
& S=c^{\prime}+\left(\sigma_{n}-\mu_{w}\right) \tan \phi^{\prime}, \\
& S=c^{\prime}+\left(\sigma_{n}-\mu_{\alpha}\right) \tan \phi^{\prime}+\left(\mu_{\alpha}-\mu_{w}\right) \tan \phi^{\prime} \frac{\theta-\theta_{r}}{\theta_{s}-\theta_{r}},
\end{aligned}
$$

where, $S$ is the degree of saturation, $\sigma_{n}$ is the normal stress; $\mu_{\alpha}$ is the dynamic viscosity of material; $\mu_{w}$ is the dynamic viscosity of water; $\theta_{w}$ is the volumetric water content; $\theta_{r}$ is the residual volumetric water content and $\theta_{s}$ is the saturate volumetric water content.

\section{Results and discussions}

\subsection{Seepage analysis}

Considering the parameters used as filling materials for construction of the dike, respective analyses are performed. Soil parameters are introduced in the Seep/W model in order to conduct respective seepage analysis. The hydrodynamics process that occurred especially during the rapid filling and drawdown has the significant impact on dike performance. Pore-water pressure and water flux per $x$-direction is investigated for three different scenarios, (Fig. 4). Regarding to first scenario (i.e. steady state condition), there is noticed a positive pore-water pressure about $35 \mathrm{kPa}$, that getting 
increase up to a distance $12 \mathrm{~m}$ according to $x$-direction, then suddenly is decreasing up to 22 according to $x$-direction, where negative pore-water pressure about $-40 \mathrm{kPa}$ is observed as result of soil unsaturation at this part of dike.
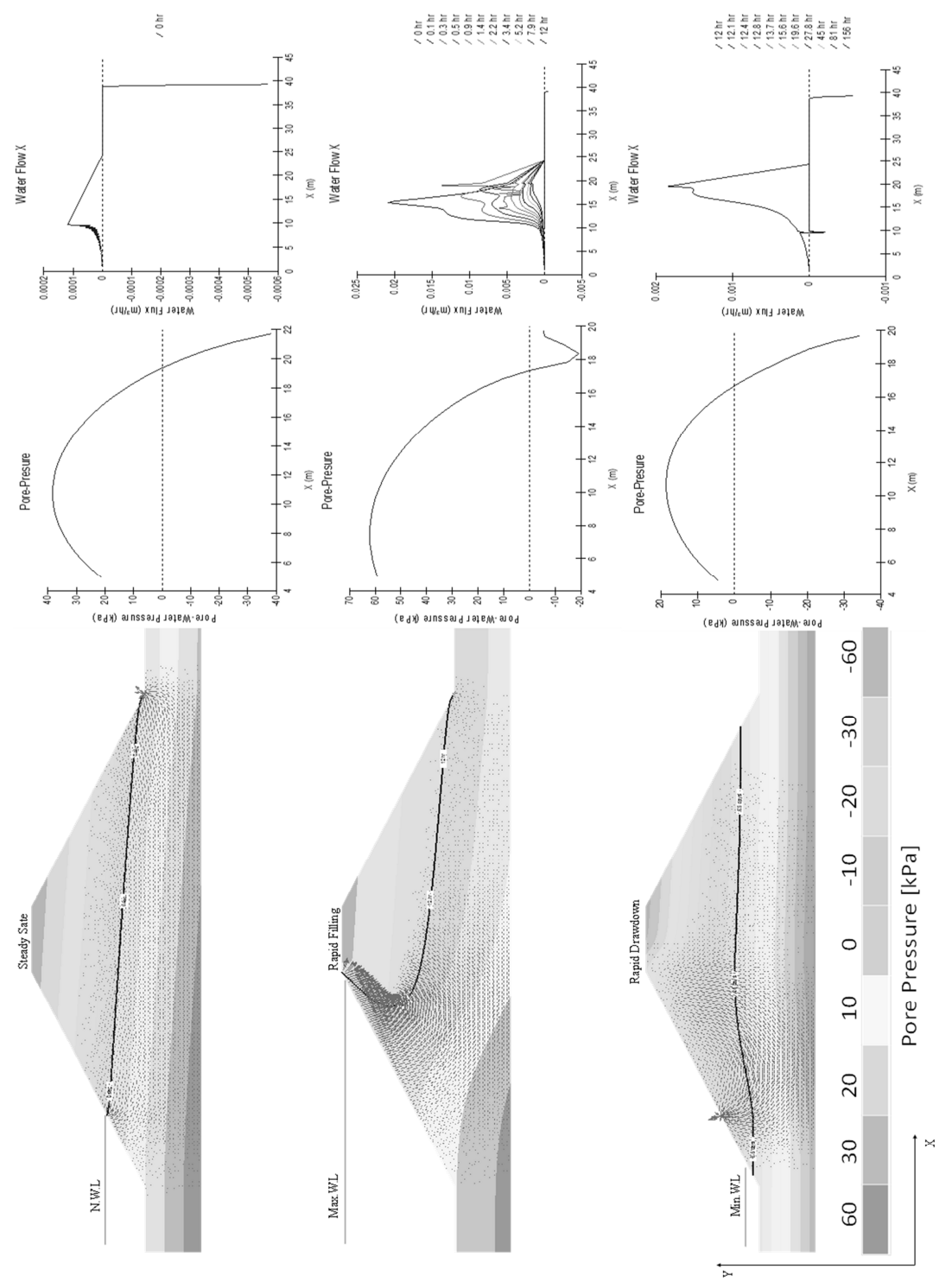

Fig. 4. Seepage analysis, pore-water pressure for three different scenarios: steady state, rapid filling and rapid drawdown 
While, maximum water flux about $1.10-4 \mathrm{~m}^{3} / \mathrm{hr}$ is reached at altitude $8.5 \mathrm{~m}$ same distance $(12 \mathrm{~m})$ according to $x$-direction, after that it is decreasing until it becomes 0 at $25 \mathrm{~m}$ distance according to $x$-direction. Concerning to the second scenario (i.e. rapid filling), there is noticed a higher pore-water pressure than the first scenario. Different from the first scenario, in this case maximum pore-water pressure about $60 \mathrm{kPa}$ is reached for shorter distance (i.e. $8 \mathrm{~m}$ ), then it is decreasing with a trend to a negative pore-water pressure about $-15 \mathrm{kPa}$ at $18 \mathrm{~m}$ distance according to $x$-direction. While maximum water flux about $2.10-4 \mathrm{~m}^{3} / \mathrm{hr}$ is reached at distance about $17 \mathrm{~m}$ after 12 hours, afterwards is decreasing until become zero at distance $25 \mathrm{~m}$ according to $x$ direction, fluctuation of water flux for respective time is presented graphically (Fig. 4), rapid filling. During the rapid drawdown, compare with the two aforementioned scenarios, it is noticed significant reduction of pore-water pressure; whereas maximum value of pore-water pressure about $15 \mathrm{kPa}$ is reached at a distance $11 \mathrm{~m}$, while drastic reduction and negative pore-water pressure is occurred as result of water withdraw from the soils and unsaturation process. Concerning to the water flux is decreasing drastically, until it becomes 0 at distance $11 \mathrm{~m}$ after $156 \mathrm{hr}$ of water withdraw at the inner part of dike structure. Detailed representation of water flux is shown at a respective graph (Fig. 4), rapid drawdown. Fluctuation of pore-water pressure and water flux according to $x$-direction for the certain time is effected from soil parameter (i.e. conductivity) and hydrodynamic processes that happening especially inside of the dike structure. Concerning to last scenarios, during rapid filling cohesion of filling material almost disappear so in these condition positive pore-water pressure is occurred while during rapid drawdown as result withdraw of water from soil particles is noticed decrease and afterwards negative pore-water pressure is occurred, (Fig. 5).

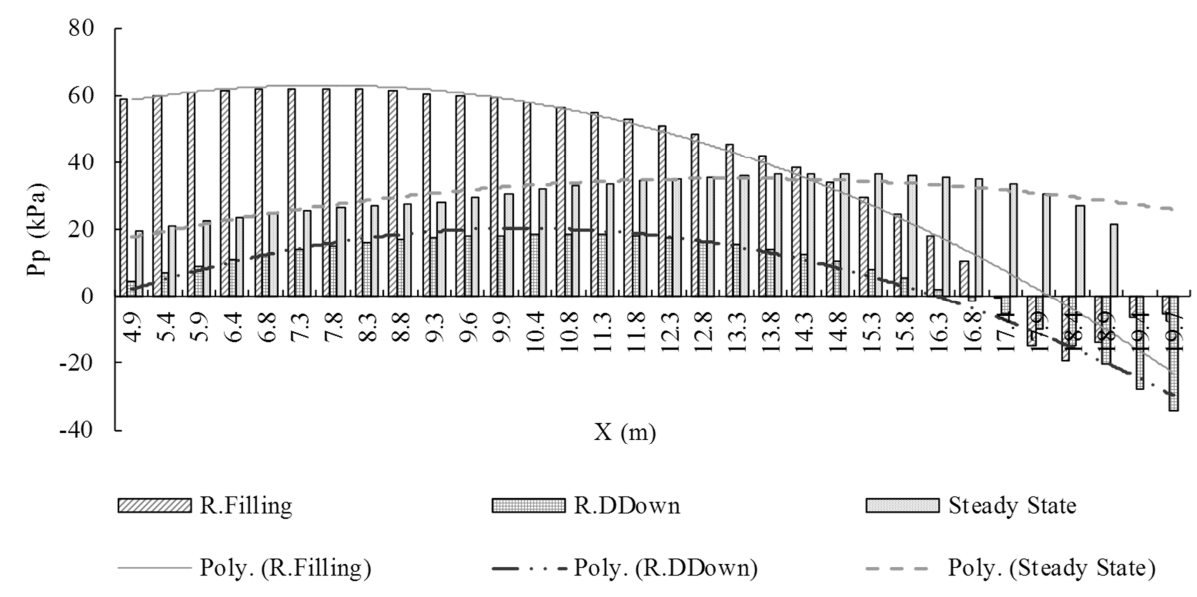

Fig. 5. Comparison of pore-water pressure occurred during steady state, rapid filling and rapid drawdown fitted with respective aforementioned polynomial functions

In addition there the correlation between pore pressure and prolongation distance of water flux is estimated along to $x$-direction. In all cases good correlation with a determination coefficient $\mathrm{R}^{2}>0.8$ is noticed. The correlation between pore pressure and 
prolongation distance is expressed through following polynomial equations, Eqs. (17), (18), (19):

$$
\begin{aligned}
& P_{p}=-0.0544 x^{2}+2.0625 x+15.631, \quad R^{2}=0.8495 \quad \text { (SteadyState), } \\
& P_{p}=-0.1343 x^{2}+1.7934 x+57.099, \quad R^{2}=0.9539 \text { (RapidFilling), } \\
& P_{p}=-0.1337 x^{2}+3.3814 x-1.0106, \quad R^{2}=0.9848 \text { (RapidDrow Down). }
\end{aligned}
$$

If during the rapid filling dike structure maintains its stability as result of hydrostatic pressure, on the other hand during rapid drawdown, dike structure is likely to fail its stability as result of seepage process which induce migration of soil particles outside the dike, [39].

\subsection{Slope stability analysis}

After seepage analysis, slope stability analysis is performed for each respective scenario. During the slope stability analysis, shear strength of soils and factor of safety is observed, (Fig. 6). Concerning to the first scenario (i.e. steady state condition), the factor of safety is about 2.45 ; it remain constant. While shear strength is getting increase about $36 \mathrm{kPa}$ up to $16 \mathrm{~m}$ distance according to $x$-direction, after that it is decreasing suddenly as the result of less consolidation of the outer side of the dike.

Regarding stability analysis for the second scenario (i.e. rapid filling); there is a significant increase related to the factor of safety especially during the first hours of rapid filling. Afterward, there is reached an equilibrium that corresponds to the factor of safety about 5.7. The sudden increase of the factor of safety is due to the temporal compaction of soils by the hydrostatic pressure. While shear strength is increasing up to the distance about $18 \mathrm{~m}$ then it is suddenly decreasing as the result of the reduction of soils strength parameter, in addition, shear strength in this scenario is lower than the first scenario. Concerning to the third scenario (i.e. rapid drawdown), it is noticed a significant decrease of a factor of safety comparing with the first and second scenario as well. Differences of safety factors regarding third scenario are about $1.2 \%$ lower than first scenario and $57 \%$ lower than a second scenario. While concerning the shear strength it is increasing about $33 \mathrm{kPa}$ up to $13 \mathrm{~m}$ distance according to $x$-direction, after that it is decreasing suddenly.

In addition, shear strength comparing with the second scenario represent higher value while comparing with the first scenario there is the significant reduction, (Fig. 7).

So, rapid change of water level at dikes structure generally lead to the degradation and reduction of soil parameters, in this condition there is a higher threat of structure failure. The correlation between shear strength and prolongation distance of the water flux along $x$-direction is estimated. In all cases is noticed good correlation with a determination coefficient $R^{2}>0.8$. 

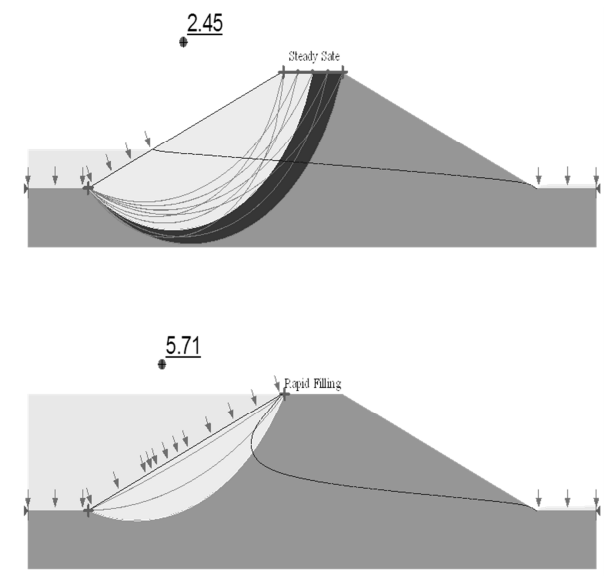

.2 .43

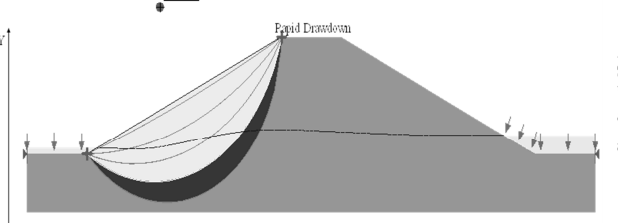

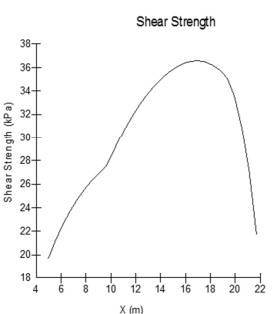

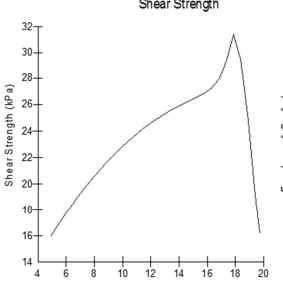

Shear Strength

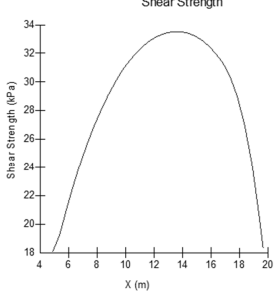

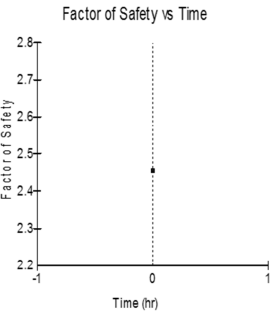

Factor of Safety is Time

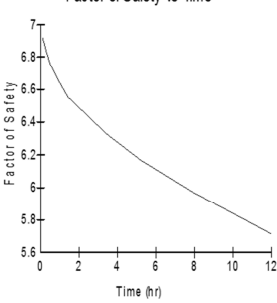

Factor of Safety is Tme

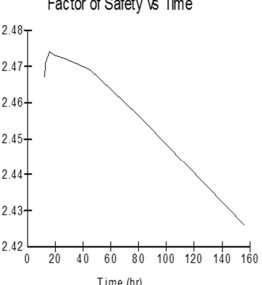

Fig. 6. Slope stability analysis, factor of safety and shear strength for three different scenarios: steady state, rapid filling and rapid drawdown

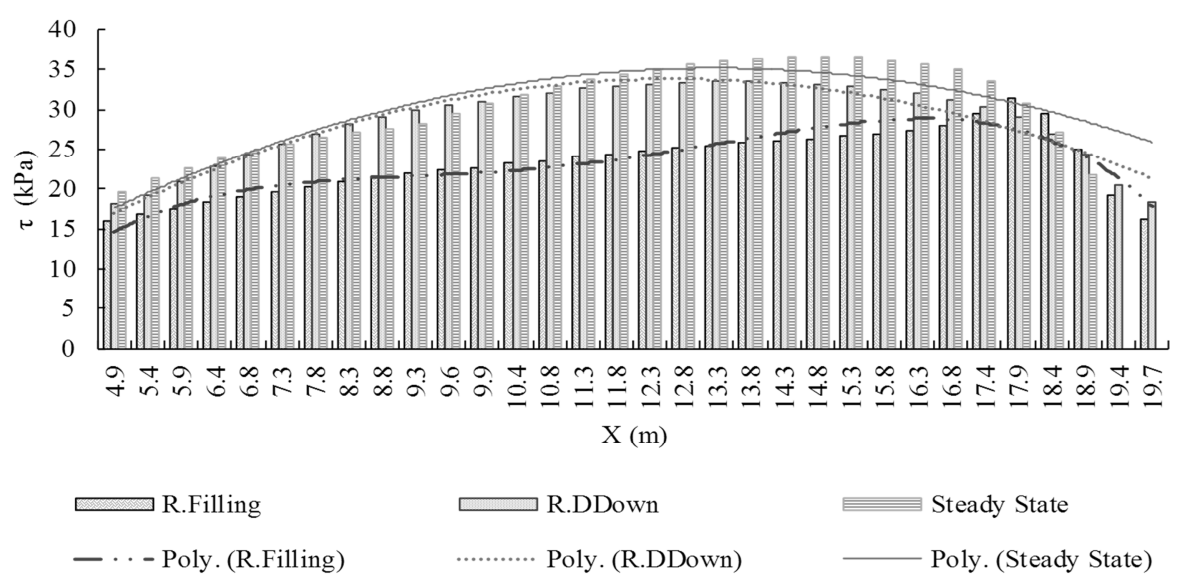

Fig. 7. Comparison of shear strength for three scenarios: steady state, rapid filling and rapid drawdown fitted with respective aforementioned polynomial functions 
The correlation between shear strength and prolongation distance i expressed through following polynomial equations, Eqs. (20), (21), (22):

$$
\begin{aligned}
& \tau=-0.0544 x^{2}+2.0625 x+15.631, \quad R^{2}=0.8495 \quad(\text { SteadyState }) \\
& \tau=-0.0003 x^{4}+0.0162 x^{3}-0.3159 x^{2}+2.7574 x+12.201 \\
& R^{2}=0.8869 \text { (Rapid Filling), } \\
& \tau=-0.0606 x^{2}+2.1403 x+14.937, \quad R^{2}=0.9539 \text { (RapidDrow Down) }
\end{aligned}
$$

\section{Conclusions}

In this paper seepage process and slope stability of dike, structure is investigated through numerical modeling for different scenarios. Scenarios considered during numerical modeling are as following: steady state, rapid filling and rapid drawdown. The investigation of seepage process during the first scenario revealed that there is certain water volume passing through the dike structure. In this case, there is no any threat concerning the stability of dike, even that presence of water inside the dike structure lead to a reduction of mechanical properties of soil. For second scenario, safety factor is increased significantly up to 5.71 but the reduction of shear strength indicates that increase of dike stability is just temporary phenomenon's that happen as result of temporary compaction of the filling materials by hydrostatic forces. Whereas during the third scenario; stability of the dike structure is decreased compared with the two first scenarios, safety factor achieved during this scenario is 2.43 . The decreasing of the factor of safety is revealed perceptibly by the significant reduction of soils parameters like; shear strength as presented on the respective graph. In this case study is noticed that during rapid filling Finally after detailed investigation of the seepage phenomenon through the dike structure, it is conclude that internal and external hydrodynamic processes and especially seepage is a serious threat that should be considered not just during design process but also operation, even that materials used for construction of the dike structure or earth structures in generally may have very good parameters. In addition, designers should be aware what kind of filling materials should be used for construction of earth structures and adaptation measures in case of structure failure. Especially for high earth structures, using silt-clay as filling materials, based on standards recommended may lead to the rapture of structure and then catastrophic disaster. Also, proper riprap layers should be considering during the design phase in order to increase the safety of dike structure and to prevent any possible failure. 


\section{References}

[1] Melnikovaa N. B., Krzhizhanovskayaa V. V., Sloot P. M. A. Modeling earthen dike stability, Sensitivity, analysis and automatic calibration of diffusivities based on live sensor data, Journal of Hydrology, Vol. 49, No. 6, 2013, pp. 154-165.

[2] Subyani A. M. Hydrologic behavior and flood probability for selected arid basins in Makkah area, western Saudi Arabia, Arabian Journal of Geosciences Vol. 4, No. 5-6, 2011, pp. 817-824.

[3] Van Baars S., Van Kempen I. M. The causes and mechanisms of historical dike failures in the Netherlands, E-Water Official Publication of the European Water Association, Delf, Netherlands, 2009.

[4] Stephens T. Manual on small earth dams: a guide to siting, design and construction, Food and Agriculture Organization of the United Nations, Rome, Italy, 2010.

[5] Fargier Y., Fauchard C., Mériaux P., Royet P., Palma-Lopes S., François D., Côte P., Bretar F. Methodology applied to the diagnosis and monitoring of dikes and dams, Novel approaches and their applications in risk assessment, Rijeka, Intechopen, 2012, pp. 263-280.

[6] Adam D., Szabó M., Paulmichl I. Innovative compaction technologies for rehabilitation of flood protection dikes, Research to Design in European Practice. Bratislava, Slovak Republic, 2-4 June, 2010, pp. 140-156.

[7] Vrijling J. K., Schweckendiek T., Kanning W. Safety standards of flood defenses, In Keynote paper at ISGSR 2011, International Symposium on Geotechnical Safety and Risk, Munich Germany, 2-3 June, 2011, pp. 67-84.

[8] Brazdova M., Riha J. A simple model for the estimation of the number of fatalities due to floods in central Europe, Natural Hazards and Earth System Science, Vol. 14, No. 7, 2014, pp. 1663-1676.

[9] Peñuela, W. F. M. River dyke failure modeling under transient water conditions, Doctoral Dissertation, Eidgenössische Technische Hochschule ETH Zürich, 2013.

[10] Sujatha E. R., Rajamanickam G. V., Kumaravel P. Landslide susceptibility analysis using probabilistic certainty factor approach, A case study on Tevankarai stream watershed, India, Journal of Earth System Science, Vol. 121, No. 5, 2012, pp. 1337-1350.

[11] Flores-Berrones R., Lopez-Acosta N. Internal erosion due to water flow through earth dams and earth structures, Rijeka, Intechopen, 2011, pp. 284-294.

[12] Camici S., Barbetta S., Moramarco T. Levee body vulnerability to seepage: the case study of the levee failure along the Foenna stream on 1st January 2006 (central Italy), Journal of Flood Risk Management, Vol. 8, No. 1, 2015, pp. 1-20.

[13] Mohamed, M. A. A., Samuels P. G., Morris M. W., Ghataora G. S. Improving the accuracy of prediction of breach formation through embankment dams and flood embankments, International Conference on Fluvial Hydraulics, Int. Assoc. of Hydraul. Eng. and Res., Vol. 2002, Louvain-la-Neuve, Belgium, 4-6 Sept, 2002, pp. 110-120.

[14] Ning B., Wu S., Tan Y., Xie X., Yan J., Yan Z., Geng Y. Coupling effect of seepage flow and river flow on the bank failure, Journal of Hydrodynamics, Ser. B, Vol. 23, No. 6, 2011, pp. 834-840.

[15] Huang M., Jia C. Q. Strength reduction FEM in stability analysis of soil slopes subjected to transient unsaturated seepage, Computers and Geotechnics, Vol. 36, No. 1, 2009, pp. 93-101.

[16] Raalte G. V. Case - wave reducing eco dike-planning and design, retrieved from deltares, Wave reducing Eco Dike Planning and Design, https://publicwiki.deltares.nl /display/BWN/Case, (last visited 15 December 2010). 
[17] Cho S. E. Probabilistic analysis of seepage that considers the spatial variability of permeability for an embankment on soil foundation, Engineering Geology, Vol. 133, 2012, pp. 30-39.

[18] Shire T., O'Sullivan C. Micromechanical assessment of an internal stability criterion, Acta Geotechnica, Vo. 8, No. 1, 2013, pp. 81-90.

[19] Borja R. I. Condition for liquefaction instability in fluid-saturated granular soils, Acta Geotechnica, Vol. 1, No. 4, 2006, pp. 211-224.

[20] Mazaeva O., Khak V., Kozyreva E. Model of erosion-landslide interaction in the context of the reservoir water level variations (East Siberia, Russia), Factors, environment and mechanisms, Journal of Earth System Science, Vol. 122, No. 6, 2013, pp. 1515-1531.

[21] Alhasan Z., Jandora J., Ř́ha J. Study of dam-break due to overtopping of four small dams in the Czech Republic, Acta Universitatis Agriculturae et Silviculturae Mendelianae Brunensis, Vol. 63, No. 3, 2015, pp. 717-729.

[22] Kádár I. Mobile flood protection walls, Pollack Periodica, Vol.10, No. 1, 2015, pp. 133-142.

[23] Rengasamy P., McLeod A. J., Ragusa S. R. Effects of dispersible soil clay and algae on seepage prevention from small dams, Agricultural Water Management, Vol. 29, No. 2, 1996, pp. 117-127.

[24] Ouria A., Toufigh M. M. Application of Nelder-Mead simplex method for unconfined seepage problems, Applied Mathematical Modeling, Vol. 33, No. 9, 2009, pp. 3589-3598.

[25] Panthulu T. V., Krishnaiah C., Shirke J. M. Detection of seepage paths in earth dams using self-potential and electrical resistivity methods, Engineering Geology, Vol. 59, No. 3, 2001, pp. 281-295.

[26] Uromeihy A., Barzegari G. Evaluation and treatment of seepage problems at Chapar-Abad Dam, Iran, Engineering Geology, Vol. 91, No. 2, 2007, pp. 219-228.

[27] Peco J., López-Querol S. Displacement based coupled model for unconfined seepage problems applied to the Gasset Dam (Ciudad Real, Spain), Engineering Geology, Vol. 137, 2012, pp. 64-73.

[28] Fu J., Jin S. A study on unsteady seepage flow through dam, Journal of Hydrodynamics, Ser. B, Vol. 21, No. 4, 2009, pp. 499-504.

[29] Ultmann Z. Comparing different mass models to the water level fluctuations of the river Danube, Pollack Periodica, Vol. 6, No. 3, 2011, pp. 107-14.

[30] De Luque, A., Porja T., Martín A., Guijarro J. A., Alonso S. A case of severe flood over Albania: a rainfall analysis from a satellite perspective, Advances in Geosciences, Vol. 7, 2006, pp. 65-72.

[31] Selenica A., Kuriqi A., Ardicioglu M. Risk assessment from flooding's in the rivers of Albania, International Balkans Conference on Challenges of Civil Engineering, Vol. 1, Tirana, Albania, 19 May 2011, pp. 1-8.

[32] MacDonald M. Medium term flood mitigation measures for lower Drini and Buna Rivers, Tirana, World Bank, 2012.

[33] Adam C., Adam D., Kopf F., Paulmichl I. Computational validation of static and dynamic plate load testing, Acta Geotechnica, Vol. 4, No. 1, 2009, pp. 35-55.

[34] Kazemzadeh-Parsi M., Daneshmand F. Three-dimensional smoothed fixed grid finite element method for the solution of unconfined seepage problems, Finite Elements in Analysis and Design, Vol. 64, 2013, pp. 24-35.

[35] Fox G. A., Wilson G. V., Simon A., Langendoen E. J., Akay O., Fuchs J. W. Measuring stream bank erosion due to ground water seepage: correlation to bank pore water pressure, precipitation and stream stage, Earth Surface Processes and Landforms, Vol. 32, No. 10, 2007, pp. 1558-1573.

[36] Krahn J. Seepage modeling with SEEP/W, Geo-Slope International, Ltd, Calgary, Canada, 2012. 
[37] Borja R. I., White J. A. Continuum deformation and stability analyses of a steep hillside slope under rainfall infiltration, Acta Geotechnica, Vol. 5, No. 1, 2010, pp. 1-14.

[38] Chapuis R. P., Aubertin M. A simplified method to estimate saturated and unsaturated seepage through dikes under steady-state conditions, Canadian Geotechnical Journal, Vol. 38, No. 6, 2001, pp. 1321-1328.

[39] Casagli N., Rinaldi M., Gargini A., Curini A. Pour water pressure and stream bank stability: results from a monitoring site on the Sieve River, Italy, Earth Surface Processes and Landforms, Vol. 24, No. 12, 1999, pp. 1095-1114. 